\title{
Examining Mathematical Creativity Among Mongolian Ninth-Grade Students Using Problem-Posing Approach
}

\author{
Otgonbaatar Khajidmaa ${ }^{1 * 2}$ \\ 1.Graduate School of Humanities and Social Sciences, Hiroshima University, 1-1-1 Kagamiyama, Higashi- \\ Hiroshima City, Hiroshima, 739-8524 Japan \\ 2.Mongolian Institute for Educational Research, 304, Teacher Development Building, Peace Avenue-10, \\ Sukhbaatar district, Ulaanbaatar, Mongolia
}

\begin{abstract}
In the 21 st century, creativity has been emphasized as one of the crucial skills needed to tackle challenges stemming from technology advancement and rapid changes in society and the labor market. Therefore, various countries include the development of creativity in their education policies and curricula. Like many other countries, the Mongolian national curriculum aims to develop creativity across the subjects. Specifically, the math curriculum emphasizes mathematical creativity as a learning outcome to be measured. The intended policies and the curricula emphasize creativity; at the same time, it has been a challenging task for educators to boost and measure creativity. The present study attempts to examine mathematical creativity among Mongolian students. Research participants were 278 ninth-grade students from urban, suburban, and rural schools in Mongolia. The students completed a mathematical problem-posing test. The study found Mongolian ninth-grade students have lower mathematical creativity. The findings suggest that students' ability to think in a variety of and novel ways should be supported through various effective teaching strategies.
\end{abstract}

Keywords: mathematical creativity, fluency, flexibility, originality, problem-posing

DOI: $10.7176 / \mathrm{JEP} / 11-27-08$

Publication date:September $30^{\text {th }} 2020$

\section{Introduction}

In the 21 st century, socio-economic changes, as well as advancements in science and technology, require individuals to have an expansive range of skills to adapt and live in today's demanding, competitive, and changing society (OECD, 2015). In response to such changes, various organizations and economies have introduced a collection of skills under the umbrella term " 21 st-century skills." The different frameworks regarding 21 st-century skills identify creativity as a prominent skill to prepare children for the changes not only in today's society but also in the future (see, e.g., National Research Council, 2012; UNESCO, 2016; Partnership for 21st-century skills, 2018). Notably, due to rapid advancement in technology, future citizens will need to think in a creative way to deal with the new challenges (Lubart and Guignard, 2004).

Therefore, education systems place greater emphasis on fostering students' creativity. According to a 2015 OECD study, a number of countries, including Norway, Sweden, Israel, Ireland, Iceland, Turkey, Japan, and South Korea, are focusing on the development of students' creativity in education system objectives and national curricula in an effort to foster creativity across the disciplines. Similarly, the Government of Mongolia approved the Proper Mongolian Child program in 2013, which aims to develop creative and confident citizens who are proficient in learning and living together as well as decision-making and who have national culture and national characteristics. The program calls for the implementation of a new curriculum in primary and secondary education. The Ministry of Education, Culture, Science and Sports (MECSS) launched the reform and introduced a new national curriculum at the primary level in 2014, at the lower secondary level in 2015, and at the upper secondary level in 2016.

The national curriculum's objective is to develop "patriotic" Mongolian citizens who are creative, confident, healthy, and proficient in decision-making, cooperating, and lifelong learning (MECSS, 2014, p. 2; MECSS, 2015, p. 18). The Government Policy in Education (2014-2024) states that "...primary education will be developed as a stage to prepare a Mongol child who is competent in the mother language and creative in learning." The policy further states that "...lower secondary education will be developed as a stage to grow life skills, basic science skills and knowledge and creative and independent learning." Therefore, the new math curriculum specifies mathematical creativity as a curriculum objective and a learning outcome to measure (MECSS, 2015, p. 45; MECSS, 2016, pp. 47-48).

Although the central policies in the education sector of Mongolia consider creativity as an essential skill that every Mongolian child should develop, at the same time, they bring about another challenge for educators who are expected to grow and measure creativity. Researchers found a lack of practice in measuring related 21st-century skills (creativity and critical thinking, etc.) at both the national and school levels in Mongolia, although such skills are incorporated into the national curriculum (Amarjargal et al., 2016). Admittedly, the measure of creativity is not a single country issue, but rather a global concern. Kyllonen (2012) stressed that some cognitive skills, such as creativity, are hard to measure. However, the National Research Council (2012) study noted that cognitive 
competencies are measured using well-established and validated testing methods. Moreover, OECD (2017) broadened the framework of mathematical literacy for Programme for International Student Assessment (PISA) 2021 by adding 21 st-century factors, including mathematical creativity.

\section{Theoretical considerations}

\subsection{Mathematical creativity}

Creativity researchers (Haylock, 1987; Sriraman, 2005; Mann, 2006) have noted that there is no commonly accepted definition of either creativity or mathematical creativity. Indeed, one study identified more than 100 contemporary definitions for creativity (Treffinger, Young, Selby and Shepardson, 2002). For example, according to Guilford (1960), creativity is represented by divergent thinking, while Poincaré (1948) defined mathematical creativity as the ability to identify and select useful combinations from useless combinations. Other researchers (Simonton, 2000; Sriraman, 2009) have defined creativity as the ability to generate original works. According to Torrance (1974):

Creativity is a process of becoming sensitive to problems, deficiencies, gaps in knowledge, missing elements, disharmonies, and so on; identifying the difficulty; searching for solutions, making guesses, or formulating hypotheses about the deficiencies; testing and retesting these hypotheses and possibly modifying and retesting them, and finally communicating the results. (p. 8)

Similarly, Laycock (1970) characterized mathematical creativity as the ability to analyze a given problem in multiple ways, notice patterns, similarities, and dissimilarities, and produce a variety of ideas based on previous experiences to deal with an unfamiliar situation. These definitions touch on different foundations. To narrow down the conceptual issues, as the central focus of the present study is to measure students' mathematical creativity, we consider mathematical creativity from the measurement perspective.

Currently, divergent thinking is the most widely applied approach to measure creative thinking (Wechsler et al., 2018). The pioneering work on creativity described by divergent thinking stemmed from Guilford's (1960) model of the structure of intellect (Wechsler et al., 2018). When he proposed the concept of divergent thinking, Guilford introduced his model as a core component of creativity. According to Guilford (1960), as far as divergent thinking is concerned, certain factors concerning creativity must be taken into consideration, such as fluency, flexibility, originality, and elaboration.

Fluency is regarded as the ability to propose numerous ideas or solutions to a problem. Flexibility refers to the ability to provide a variety of ideas or solutions to a problem. Originality is represented by the ability to produce novel or unique ideas or solutions to a problem. Elaboration refers to the ability to give detailed steps to widen ideas or solutions to a problem (e.g., see, Guilford, 1960; Torrance, 1966, 1974;).

As previously mentioned, most current measures of creativity rely on the notion of divergent thinking. For instance, Torrance's (1966) widely used creativity test is based on Guilford's four divergent thinking factors. Moreover, mathematical researchers, such as Chamberlin and Moon (2005), agreed that divergent thinking is one of the prevailing descriptors of mathematical creativity. A considerable number of studies in mathematics education have used the concept of divergent thinking by focusing on fluency, flexibility, and originality to measure mathematical creativity (e.g., see, Wardani et al., 2010; Yuan and Sriraman, 2012; Katou et al., 2015).

\subsection{Problem-posing}

Jensen (1973) found that students' ability to pose mathematical problems or questions is related to creativity. Mathematical problem-posing is defined as the process by which students generate relevant problems from given situations or information based upon their mathematical experience (Yuan and Sriraman, 2012). For example, students receive a graph or a bar chart and are asked to write down as many questions as possible related to the given information (e.g., see, Prouse, 1964; Jensen, 1973; Balka, 1974). Silver (1997) noted that problem-posing is a suitable approach for identifying students' creative thinking. Therefore, problem-posing enables researchers to identify mathematical creativity while simultaneously growing students' core components of creativity, such as fluency, flexibility, and originality (Torrance, 1988; Silver, 1997). 


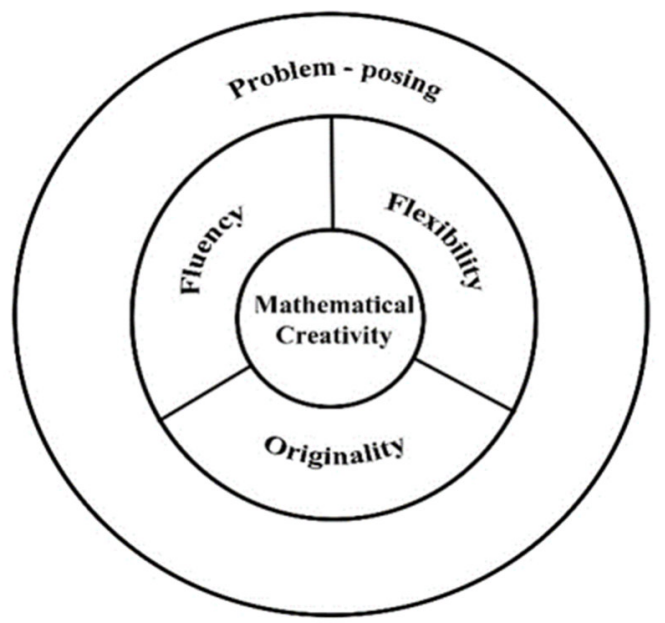

Figure 1. The Conceptual Framework (developed by the author)

Thus, the present study attempts to examine mathematical creativity by focusing on fluency, flexibility, and originality using a problem-posing approach (Figure 1).

\section{Methodology}

\subsection{Participants}

This study included a sample of 278 ninth-grade students from urban, suburban, and rural schools in Mongolia. The sample consisted of 51\% girls and $49 \%$ boys, with an average age of 14 . All schools in this study were public schools that have been implementing the new national curriculum since 2014.

\subsection{Measure and Procedure}

We used a mathematical problem-posing test consisting of three problem-posing tasks (Table 1). The tasks were selected based on the Mongolian Grade 9 math curriculum and textbook content.

Table 1. Mathematical problem-posing tasks

\begin{tabular}{|c|l|c|}
\hline № & \multicolumn{1}{|c|}{ Task } & \multicolumn{1}{c|}{ Source of the Task } \\
\hline 1 & $\begin{array}{l}\text { Make as many groups of numbers as you can, using the } \\
\text { numbers given below. Label each group with its } \\
\text { characteristics. } \\
2,3,7,9,13,15,17,25,36,39,49,51,60,64,91,119, \\
121,125,136,143,150\end{array}$ & $\begin{array}{c}\text { A free-structured problem-posing task } \\
\text { from Kattou et al. (2015) }\end{array}$ \\
\hline \multirow{2}{*}{3} & $\begin{array}{l}\text { Last night there was a party at your cousin's house, and the } \\
\text { doorbell rang ten times. The first time the doorbell rang, } \\
\text { only one guest arrived. Each time the doorbell rang, three } \\
\text { more guests arrived than had arrived on the previous ring. } \\
\text { Ask many questions as you can that are in some way } \\
\text { related to this problem. }\end{array}$ & $\begin{array}{c}\text { A structured problem-posing task from } \\
\text { Stoyanova (1997) and Cai (2000) in Yuan } \\
\text { \& Sriraman (2012) }\end{array}$ \\
\hline $\begin{array}{l}\text { In the picture below, there is a triangle and its inscribed } \\
\text { circle. Make up as many problems as you can that are in } \\
\text { some way related to this picture. }\end{array}$ & $\begin{array}{c}\text { A semi-structured problem-posing task } \\
\text { from Stoyanova (1997) in Yuan \& } \\
\text { Sriraman (2012) }\end{array}$ \\
\hline
\end{tabular}

Before administering the test, the researchers asked a math curriculum developer (Mongolian Institute for Educational Research), a math textbook author (Mongolian Institute for Educational Research), and an evaluation specialist (Education Evaluation Center) to evaluate the appropriateness of the instrument. The test was then 
administered to the participants for a period of 40 minutes during regular classroom activities. The data were collected in the paper-and-pencil form and entered into Microsoft Word and Microsoft Excel documents.

\subsection{Data analysis}

The present study employed the following scoring method suggested by Kattou et al. (2012):

a) Fluency score is represented by the ratio between the number of correct mathematical problems that the student produced, and the maximum number of correct mathematical problems produced by a student in the sample.

b) Flexibility score is represented by the ratio between the number of different types of correct problems that the student produced and the maximum number of different types of problems produced by a student in the sample.

c) Originality score is represented by the rareness or uniqueness of a student's responses in the sample. The scoring criteria are presented in Table 2.

Table 2. Scoring criteria for originality

\begin{tabular}{|c|c|}
\hline Criteria & Score \\
\hline If the responses occur in less than $2 \%$ of the sample's responses & 1 \\
\hline If the responses occur in $2 \%$ to $5 \%$ of the sample's responses & 0.8 \\
\hline If the responses occur in $6 \%$ to $10 \%$ of the sample's responses & 0.6 \\
\hline If the responses occur in $11 \%$ to $20 \%$ of the sample's responses & 0.4 \\
\hline If the responses occur in more than $20 \%$ of the sample's responses & 0.2 \\
\hline
\end{tabular}

Therefore, three different scores are produced for each student in each task. The total score of the test is derived by adding the fluency, flexibility, and originality scores on the three tasks and converting the sum to a scale ranging from 0 to 1 .

Some non-mathematical responses were eliminated from the analysis (e.g., responses such as "my favorite numbers" for Task 1; "Please find whose birthday it was. How can we find it?" and "Were all the guests classmates?" for Task 2; and "Why is this circle inside the triangle?" and "The triangle is stronger than the circle since it is bigger than the circle. Is it true?" for Task 3). The data were analyzed using Microsoft Excel and SPSS 20.0 .

\section{Results and Discussion}

First, we analyzed the students' ability to produce correct problems in relation to the given situations. For Task 1 , the majority of the students (68\%) provided up to five correct problems, $28.8 \%$ gave 5 to 10 correct problems, and $3.2 \%$ gave 10 or more correct problems. In total, the respondents posed 1020 correct problems for Task 1 (Table 3 ). For Task $2,87.8 \%$ of the students posed up to 5 correct problems, $8.2 \%$ provided 5 to 10 correct problems, and $4 \%$ posed 10 or more correct problems. Altogether, the respondents provided 672 correct problems for Task 2 (Table 3). For Task 3, 86.7\% of the respondents posed up to 5 correct problems, and $13.3 \%$ gave 5 or more correct problems. In sum, the respondents posed 680 correct problems (Table 3 ).

Next, we examined how many different types of problems the respondents provided for each task. For Task $1,51 \%$ of the respondents provided only one type of problem, and $42 \%$ of the respondents posed $2-3$ different types of problem. Only $7 \%$ of the respondents gave four or more types of problems. In general, all the problems that the respondents provided for Task 1 could be classified into seven types of problems (Table 3 ). For Task 2 , $96.8 \%$ of the respondents posed 1 to 2 different types of responses, and only $3.2 \%$ gave 3 different types of problems. All the problems that the respondents provided for Task 2 could be grouped into six types of problems (Table 3). For Task 3, 69\% of the respondents gave 1 to 2 different types of problems, and $31 \%$ posed 3 to 6 different types of problems. Overall, the problems that the respondents produced for Task 3 could be categorized into eight types of problems (Table 3 ).

Table 3. Overall performance on the problem-posing test

\begin{tabular}{|c|c|c|}
\hline Task & Total number of responses & Number of different types of responses \\
\hline 1 & 1020 & 7 \\
\hline 2 & 672 & 6 \\
\hline 3 & 680 & 8 \\
\hline
\end{tabular}

These findings indicate that a large percentage of students struggled with posing different types of problems; however, they were able to produce a number of correct problems.

Third, we explored how original students' responses were. For originality, Kumar (2012) suggested that the responses produced by less than 5\% of the sample could be considered original. According to this rule, $15.8 \%$ of the responses for Task 1, 17.6\% for Task 2, and 16\% for Task 3 were identified as original. Examples of original responses included "Three-digit numbers with a sum of its digits are smaller than one and two-digit numbers (121; $115 ; 150)$ " for Task 1 , "Is it possible that the number of guests can be a prime number? If possible, at which number of doorbell ring, the number of guests can be a prime number?" for Task 2, and "If the diameter of the circle and 
cathetus of the triangle are known, is it possible to find the angles of the triangle? Please prove it" for Task 3. Table 4 presents the overall performance on the mathematical problem-posing test.

Table 4. Overall performance on the problem-posing test

\begin{tabular}{|c|c|c|c|c|c|}
\hline Task & Fluency (mean) & $\begin{array}{c}\text { Flexibility } \\
(\text { mean })\end{array}$ & $\begin{array}{c}\text { Originality } \\
(\text { mean })\end{array}$ & Total score & $\begin{array}{c}\text { Test score } \\
(0-1)\end{array}$ \\
\hline 1 & 0.24 & 0.25 & 0.22 & \multirow{2}{*}{2.54} & 0.28 \\
\hline 2 & 0.14 & 0.42 & 0.27 & & \\
\hline Average & 0.30 & 0.33 & 0.37 & & \\
\hline
\end{tabular}

Note: Ideal score for each task is 3 and the total score is 9.

As Table 4 indicates, students earned an average score of 2.54 on the mathematical problem-posing test or 0.28 on the $0-1$ scale. These results confirmed that the students lacked mathematical creativity. Several concerns could be discussed regarding the students' low level of mathematical creativity. Firstly, appropriate teaching strategies are crucial to growing mathematical creativity. Soedjadi (2000, as cited in Wardani, Sumarmo, and Nishitani, 2011) stressed that students' low level of mathematical creativity is linked to inappropriate teaching strategies that do not allow students to develop their mathematical understanding. Moreover, researchers (Grégoire, 2016; Sumarmo, 2005, as cited in Wardani, Sumarmo, and Nishitani, 2011) urged that, in addition to having better mathematical knowledge, teachers should be capable of using effective teaching strategies and approaches suitable for specific topics and skills to be developed. Thus, it is important to develop curricula that support students' mathematical creativity; at the same time, it is vital to understand the development of mathematical creativity from theoretical perspectives. Consequently, teaching strategies, learning activities and tasks, and the learning environment should be designed to grow students' mathematical creativity.

Secondly, Mongolian students might be unfamiliar with problem-posing tasks. The researchers noted that teachers give more emphasis to routine mathematical tasks while neglecting creative mathematical thinking (Wardani, Sumarmo, and Nishitani, 2011). Nevertheless, students' mathematical creativity can be fostered by experiencing posing problems and working with ill-posed and open-ended problems and solving interesting and challenging tasks (Grégoire, 2016; Wardani, Sumarmo, and Nishitani, 2011).

Finally, one limitation of this study is that it examined mathematical creativity from only the psychometric perspective. According to Sternberg (1998), the psychometric approach offers both advantages and disadvantages. Notably, the psychometric approach, such as the creativity test and tasks, is easy to administer and objectively score (Sriraman, 2009). Yet it is often criticized that the numerical score of short paper-and-pencil tests may neglect the concept of creativity (Sriraman, 2009). Furthermore, the distribution of the score derived from the test can be drastically affected by an individual's response. For instance, if there is one gifted student in the sample and he or she provides many different types of problems, other respondents' score could be much lower, as the score is found by comparing a response to the maximum number of different types of problems in the sample according to the scoring rule.

\section{Conclusion}

The present study sought to examine mathematical creativity among Mongolian students using a mathematical problem-posing test. The results indicated that Mongolian ninth-grade students have lower mathematical creativity. However, the intended policies and curriculum have emphasized the development of mathematical creativity.

In light of the above concerns and limitation, future studies should offer some insights into curriculum implementation by examining textbook tasks and learning activities as well as teaching strategies and classroom practices in Mongolia from the perspectives of developing mathematical creativity. In particular, future studies could investigate if the teaching strategies, textbook tasks, and learning environment support students' mathematical creativity by allowing them to think in a variety of and novel ways. Apart from the numerical outputs, future studies could also examine mathematical creativity based on other essential outputs, such as modelling and drawing.

\section{Acknowledgment}

The author thanks Densmaa Jargalsaikhan and Tuvhsinjargal Dugarjav of the Mongolian Institute for Educational Research, Gantuya Mendbayar of the Education Evaluation Center in Mongolia for their valuable contribution to select the problem-posing tasks in this study. A special thanks goes to Tsetsegjargal Khulganaa of the Mongolian Institute for Educational Research for her helpful comments and kind assistance with the data collection. The author also thanks the school principals and teachers for allowing us to collect the data. The financial support of the Japan International Cooperation Agency (JICA) is gratefully acknowledged.

\section{References}

Amarjargal, A., Munkhjargal, D., Khishigbayar, B., \& Otgonbaatar, Kh. (2016). "Policy and implementation of 
assessment of new competencies", Proceedings of International Conference on Educational Evaluation (pp. 100-105). Ulaanbaatar, Mongolia: Soyombo Printing.

Balka, D. S. (1974). "Creative ability in mathematics", The Arithmetic Teacher, 21, 633-363.

Cai, J. (2000). "Mathematical thinking involved in U.S. and Chinese students' solving of process-constrained and process-open problems", Mathematical Thinking and Learning, 2(4), 309-340. https://doi.org/10.1207/s15327833mt10204_4

Grégoire, J. (2016). "Understanding creativity in mathematics for improving mathematical education", Journal of Cognitive Education and Psychology, 15(1), 24-36. https://doi.org/10.1891/1945-8959.15.1.24

Guilford, J. P. (1960). "The structure of the intellect model: Its use and implications", New York: McGraw-Hill.

Haylock, D. (1987). "A framework for assessing mathematical creativity in schoolchildren", Educational Studies in Mathematics, 18(1), 59-74. https://doi.org/10.1007/bf00367914

Jensen, L. R. (1973). "The relationships among mathematical creativity, numerical aptitude, and mathematical achievement", Unpublished dissertation. The University of Texas at Austin, Austin.

Kattou, M., Kontoyianni, K., Pitta-Pantazi, D., \& Christou, C. (2012). "Connecting mathematical creativity to mathematical ability", ZDM, 45(2), 167-181. https://doi.org/10.1007/s11858-012-0467-1

Kattou, M., Christou, C., \& Pitta-Pantazi, D. (2015). "Mathematical creativity or general creativity?", In Ninth Congress of the European Society for Research in Mathematics Education (pp.1016-1023). Prague, Czech Republic. Retrieved from https://hal.archives-ouvertes.fr/hal-01287305/document

Kumar, L. (2012). "Fostering mathematical creativity", Retrieved 7 July 2020, from http://www.ncert.nic.in

Kyllonen, P. (2012). "Measurement of 21 st century skills within the common core state standards", In Invitational Research Symposium on Technology Enhanced Assessments. Education Testing Center, Princeton. Retrieved from https://www.ets.org/Media/Research/pdf/session5-kyllonen-paper-tea2012.pdf.

Laycock, M. (1970). "Creative mathematics at Nueva", The Arithmetic Teacher, 17, 325-328. Retrieved 9 July 2020, from https://www.jstor.org/stable/41186201?seq=1\#metadata_info_tab_contents

Lubart, T. \& Guignard, J. H. (2004). "The generality-specificity of creativity: A multivariate approach", In R. J. Sternberg, E. L. Grigorenko, \& J. L. Singer (Eds.), Creativity: From potential to realization (pp. 43-56). Washington, D.C.: American Psychological Association.

Mann, E. (2006). "Creativity: The essence of mathematics", Journal for The Education of The Gifted, 30(2), 236260. https://doi.org/10.4219/jeg-2006-264

Ministry of Education, Culture, Science and Sports. (2014). "Primary education core curriculum", Retrieved 12 May 2020, from https://mecss.gov.mn/news/95/

Ministry of Education, Culture, Science and Sports. (2015). "Lower secondary education core curriculum", Retrieved 12 May 2020, from https://mecss.gov.mn/news/94/

Ministry of Education, Culture, Science and Sports. (2016). "Upper secondary education core curriculum", Retrieved 12 May 2020, from http://www.mier.mn/wp-content/uploads/2018/11/Math-2.pdf

National Research Council. (2012). "Education for life and work: Developing transferable knowledge and skills in the 21st century", Washington, DC: National Academies Press. Retrieved 15 June 2020, from https://www.nationalacademies.org/our-work/defining-deeper-learning-and-21st-century-skills

OECD. (2015). "Skills for Social Progress: The power of social and emotional skills, OECD skills studies", Retrieved 25 April 2020, from https://doi.org/10.1787/9789264226159-en.

OECD. (2017). "PISA 2021 Mathematics: A broadened perspective", Retrieved 18 April 2020, from https://www.oecd.org/pisa/pisaproducts/PISA2021_Mathematics_StrategicDirectionPaper.pdf

Partnership for 21st Century Skills. (2009). "P21 framework definitions", Retrieved 17 April 2020, from https://eric.ed.gov/?id=ED519462

Poincaré, H. (1948). "Science and method", New York: Dover.

Prouse, H. L. (1964). "The construction and use of a test for the measurement of certain aspects of creativity in seventh-grade mathematics", Dissertation Abstracts, 26 (01), 394.

Silver, E. (1997). "Fostering creativity through instruction rich in mathematical problem solving and problem posing”, Zentralblatt Für Didaktik Der Mathematik, 29(3), 75-80. https://doi.org/10.1007/s11858-997-0003$\mathrm{x}$

Simonton, D. (2000). "Creativity: Cognitive, personal, developmental, and social aspects", American Psychologist, 55(1), 151-158. https://doi.org/10.1037/0003-066x.55.1.151

Sriraman, B., \& Lee, K. (2011). "The elements of giftedness and creativity in mathematics", Rotterdam, The Netherlands: Sense Publishers.

Sriraman, B. (2005). "Are giftedness and creativity synonyms in mathematics?", Journal of Secondary Gifted Education, 17(1), 20-36. https://doi.org/10.4219/jsge-2005-389

Sriraman, B. (2009). "The characteristics of mathematical creativity", ZDM Mathematics Education 41, 13. https://doi.org/10.1007/s11858-008-0114-z

Sternberg, R. (Ed.). (1998). "Handbook of Creativity", Cambridge: Cambridge University Press. 
https://doi:10.1017/CBO9780511807916

Stoyanova, E. (1997). "Extending and exploring students' problem solving via problem posing: A study of years 8 and 9 students involved in mathematics challenge and enrichment stages of Euler enrichment program for young Australians", Unpublished doctoral dissertation submitted to Edith Cowan University, Perth, Australia.

The Government of Mongolia. (2013). "Proper Mongolian Child Program”, Retrieved 12 May 2020, from https://www.legalinfo.mn/annex/details/5962?lawid=9349

The Parliament of Mongolia. (2015). "The Government Policy in Education”, Retrieved 12 May 2020, from https://www.legalinfo.mn/annex/details/6661?lawid=10935

Torrance, E. P. (1966). “Torrance Tests of Creative Thinking: Norms technical manual”, Princeton, NJ: Personnel Press.

Torrance, E. P. (1974). “Norms-technical manual: Torrance Tests of Creative Thinking”, Lexington, MA: Ginn and Company.

Torrance, E. P. (1988). "The nature of creativity as manifest in its testing", In R. J. Sternberg (Ed.), The nature of creativity: Contemporary psychological perspectives (pp. 43-75). New York: Cambridge University Press.

Treffinger, D. J., Young, G. C., Selby, E.C., \& Shepardson, C. (2002). "Assessing creativity: A guide for educators (RM02170)", Storrs, CT: The National Research Center on the Gifted and Talented, University of Connecticut.

UNESCO. (2016). "Assessment of transversal competencies: Current tools in the Asian region", Retrieved from https://bangkok.unesco.org/content/assessment-transversal-competencies-current-tools-asian-region

Van Harpen, X., \& Sriraman, B. (2012). "Creativity and mathematical problem posing: An analysis of high school students' mathematical problem posing in China and the USA", Educational Studies in Mathematics, 82(2), 201-221. https://doi.org/10.1007/s10649-012-9419-5

Wardani, S.B., Sumarmo, U., \& Nishitani, I. (2011). "Mathematical creativity and disposition: experiment with grade-10 students using silver inquiry approach", https://gair.media.gunma-u.ac.jp

Wechsler, S., Saiz, C., Rivas, S., Vendramini, C., Almeida, L., Mundim, M., \& Franco, A. (2018). "Creative and critical thinking: Independent or overlapping components?", Thinking Skills and Creativity, 27, 114-122. https://doi.org/10.1016/j.tsc.2017.12.003 